Supplementary Material to

\title{
Assessing impacts on the natural resource soil in Life Cycle Assessment - methods for compaction and water erosion
}

\section{Thomas Sonderegger*, Stephan Pfister, Stefanie Hellweg}

Chair of Ecological Systems Design, Institute of Environmental Engineering, ETH Zurich

*sonderegger@ifu.baug.ethz.ch,+41446336014

28 Pages

12 Figures

6 Tables 


\section{Contents}

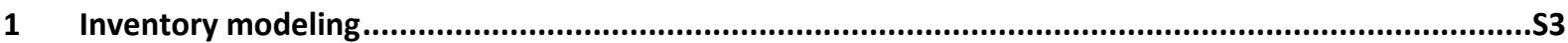

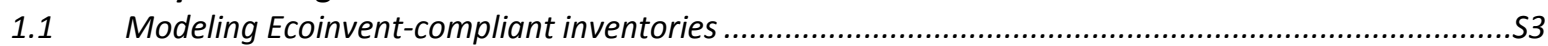

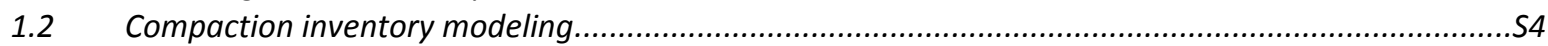

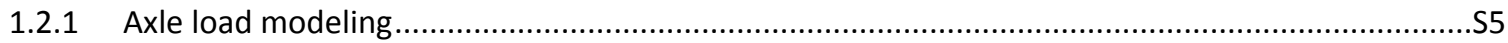

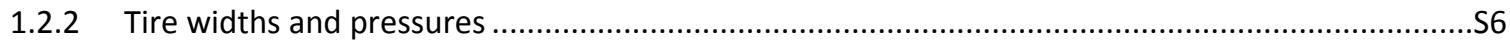

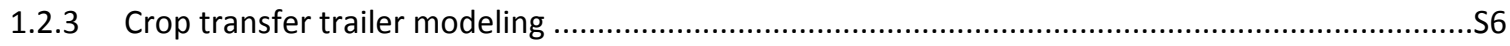

1.2.4 Adapting the number of passes for case study "crop production activities"...............................S6

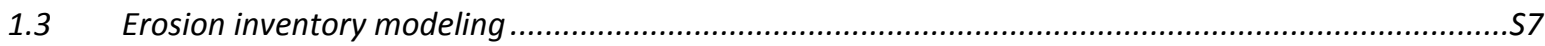

$1.4 \quad$ Attaching compaction- and erosion-modeling to Ecoinvent activities .............................................S7

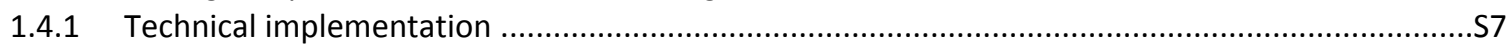

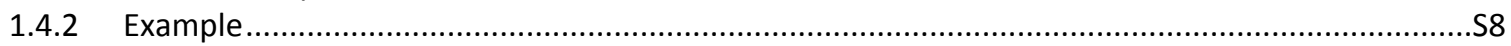

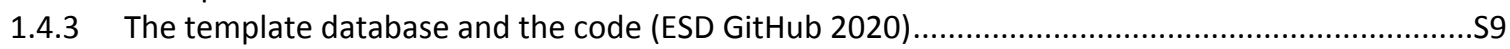

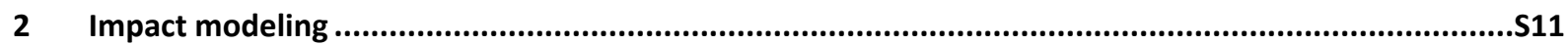

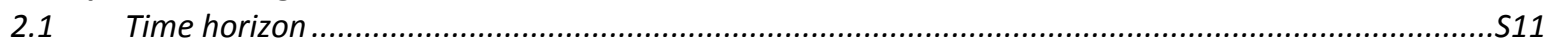

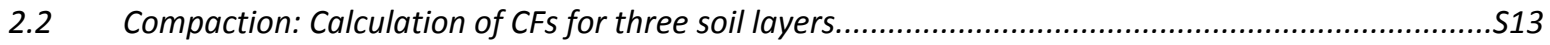

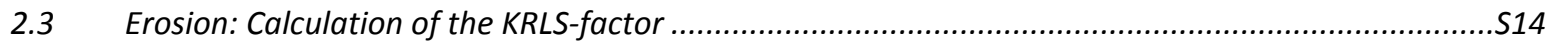

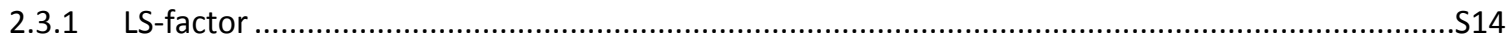

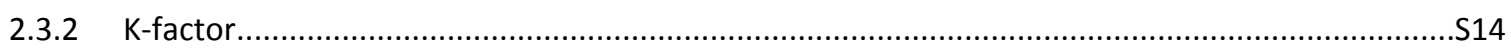

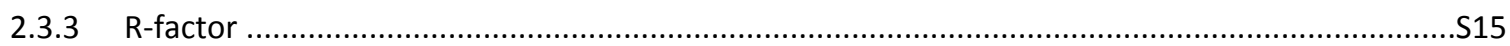

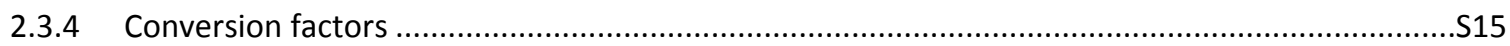

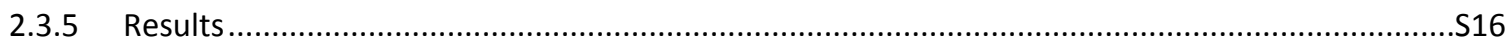

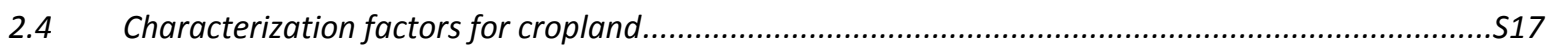

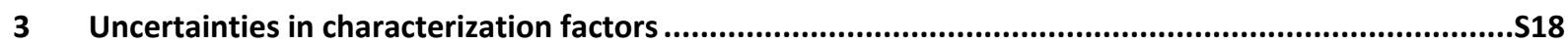

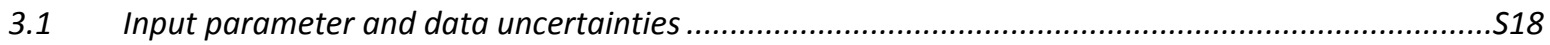

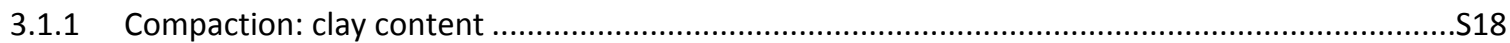

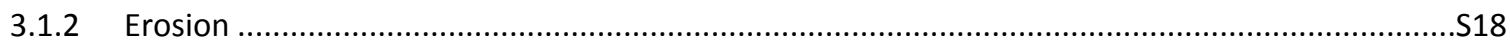

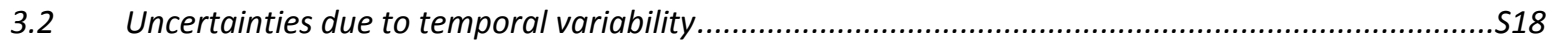

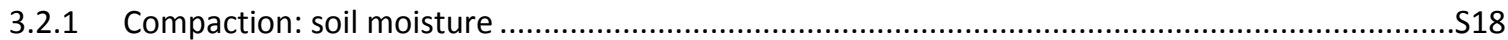

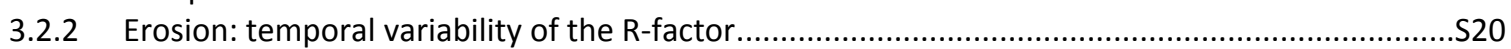

3.3 Accounting for spatial variability in aggregated CFs ...............................................................S20

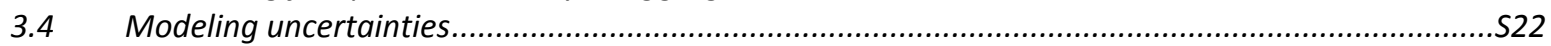

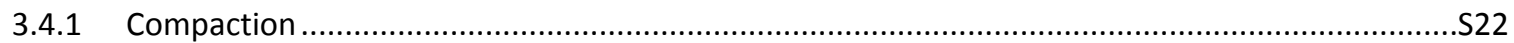

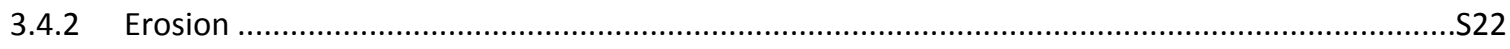

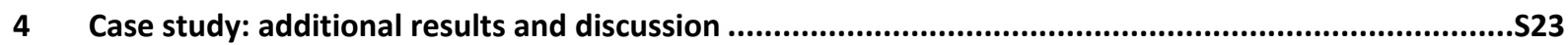

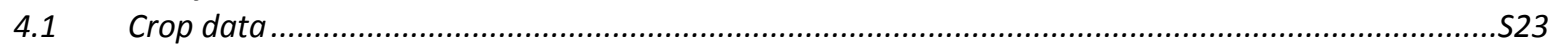

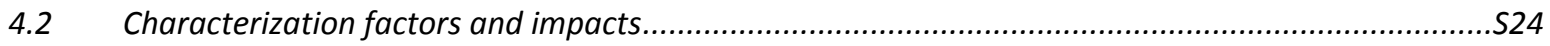

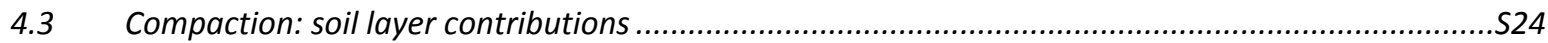

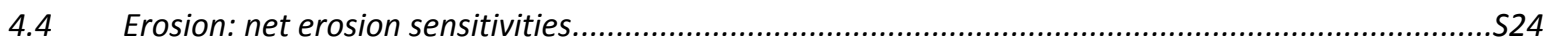

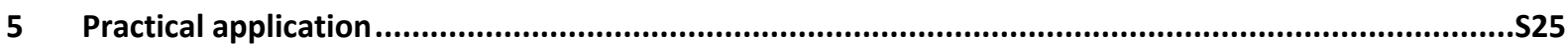

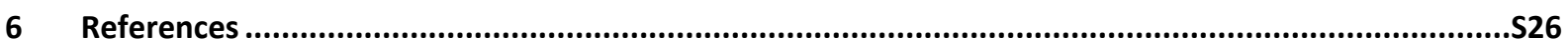

Code is available@https://github.com/ethz-esd/compaction_erosion_sonderegger_2020 


\section{Inventory modeling}

The reference inventory database used is Ecoinvent 3.5 (Ecoinvent 2018). Compaction and erosion relevant data (from Ecoinvent and additional) was organized in an Excel database whose structure follows the Ecoinvent modeling framework (see 1.1). On the one hand, this allows attaching necessary parameters to existing Ecoinvent processes; on the other hand, this facilitates modeling Life Cycle Inventores (LCIs) of new processes in a way that is compatible with existing Ecoinvent processes, which allows for an assessment of soil degradation processes in the foreground and the background system. Inventory data was collected in Excel databases, which are available in SI2 and SI3. In SI2, machinery data from online sources was collected in order to create machinery datasets for small, medium, and large "fieldwork process activities" used for the case study. These datasets are based on machinery equal or similar to what has been used in Gazzarin (2018), which was also the basis for Ecoinvent datasets. Small and medium activities are therefore representative for Switzerland today and medium and large activities might be representative where agriculture is practiced at larger scale. Original "fieldwork process" inputs into existing Ecoinvent "crop production activities" have been replaced by created "fieldwork process activities" in order to create three management scenarios for small, medium, and large "crop production activities" (SI3). The database in SI3 further includes the axle load modeling and prepares all data for use in a code where the inventory part of the TONKM model is run (equations can be found in SI4 or in the code on GitHub (ESD GitHub 2020). Additional information and modeling for existing Ecoinvent activities, e.g. machine weights and axle load modeling, is also organized in this database so compaction and erosion impacts can be assessed.

\subsection{Modeling Ecoinvent-compliant inventories}

The erosion and compaction relevant activities in Ecoinvent are "crop production activities" and the agricultural "fieldwork process activities" (Figure S1, left side). The "fieldwork process activities" are an input from technosphere (via markets) into crop production. The right side of Figure S1 shows the different parts of the provided template database and where models are attached to: the erosion model (RUSLE) is attached to "crop production activities" and the compaction model (TONKM) is attached to "fieldwork process activities". The provided template database allows modeling all necessary "fieldwork process activities" for crop production including their inputs and emissions. It further extends the inventory by the data needed for compaction and erosion modeling.

The modeling of agricultural activities in Ecoinvent is described in Nemecek and Kägi (2007). In the provided template database (SI3), new "fieldwork process activities" can be added and all corresponding technosphere inputs and emissions will be modeled (as indicated by the dark green boxes in Figure S1). A fieldwork process is basically a combination of powered and attached agricultural machines, e.g. a tractor with a plough. In the template database, machinery information is kept separately to allow different combinations. 
In contrast to "fieldwork process activities", for which modeling is rather complete (at least as complete as it is done in Ecoinvent), the modeling of "crop production activities" is only partly addressed in the template database (as indicated by the light green boxes in Figure S1). With regard to regionalization, the markets for "fieldwork process activities" as implemented in Ecoinvent 3.5 are a problem as only few regions are included, e.g. Switzerland, Quebec (Canada), and "Rest of the World". Therefore, the modeling (in a later step) avoids the markets but directly attaches "fieldwork process activities" to "crop production activities" in a specific region.
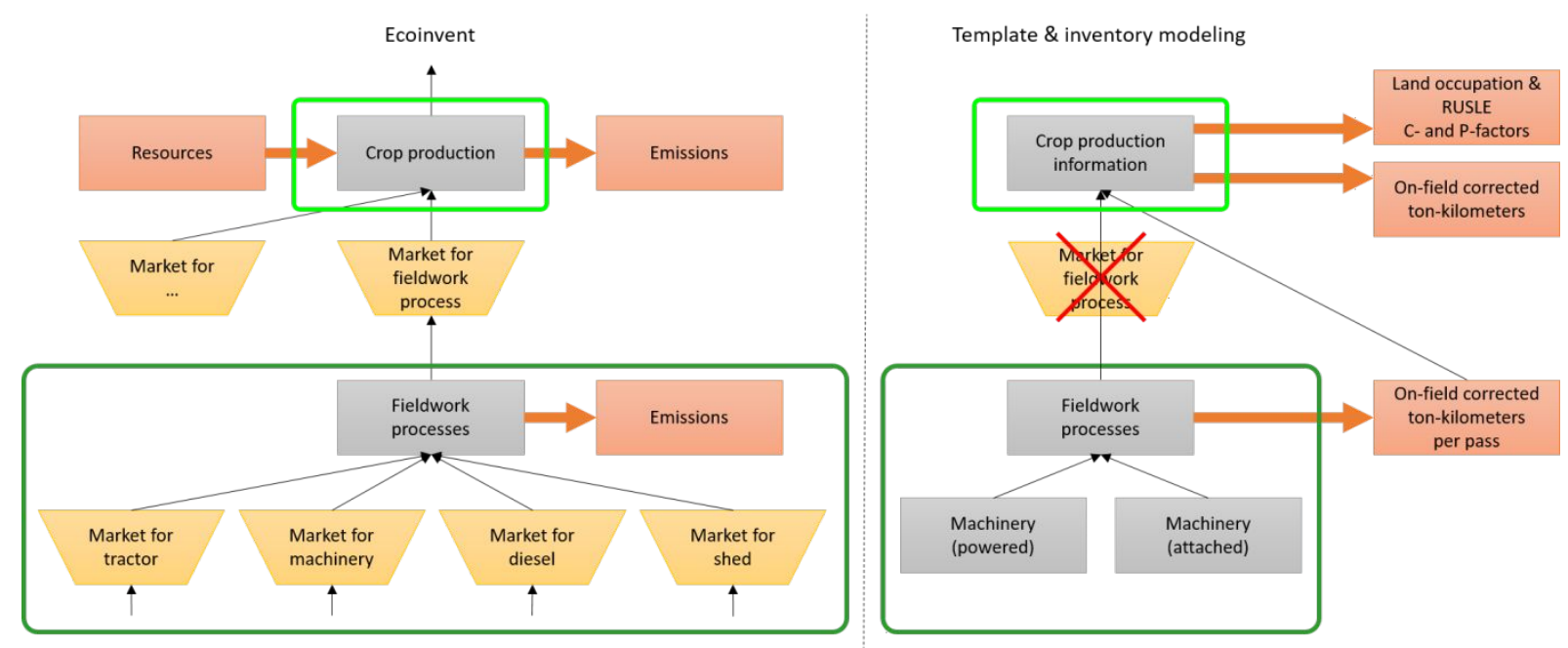

Figure S1: Modeling of agricultural activities in Ecoinvent and in the study; dark green: compaction modeling; light green: erosion modeling

In order to model a complete crop production inventory, the following aspects according to Nemecek and Kägi (2007) need to be considered additionally to those covered by the template database and its inventory modeling:

- Co-products (and according allocation) and crop residues (and according fertilizer use)

- Fertilizers

- Pesticides

- $\quad$ Seed

- Transports

- Land use (occupation and transformation)

- Direct field emissions

- Data Quality Considerations

Crop residues management is also a factor in the RUSLE erosion modeling and the assumptions would need to be aligned.

\subsection{Compaction inventory modeling}

The TONKM model used for compaction is based on Arvidsson and Håkansson (1991). The basic model structure is

tkm (corrected) ${ }^{*}$ Soil moisture factor * Clay factor $=$ Yield Loss 
whereby the tkm are the inventory part of the model and calculated as

Distance $($ corrected $){ }^{*}$ Weight $($ corrected $){ }^{*}$ Tire pressure factor $=\mathrm{tkm}($ corrected $)$

The TONKM model has already been adapted for use in LCA by Stoessel et al. (2018), re-structuring the formulas for use in a Python (2019) code. These formulas were further adjusted to be compatible with the axle load modeling needed for calculation of corrected weight as described further below. The complete original and adapted formulas are documented in SI4.

The inventory part of the model is applied to three different soil layers (top soil: 0-25 cm, mid soil: 25 -

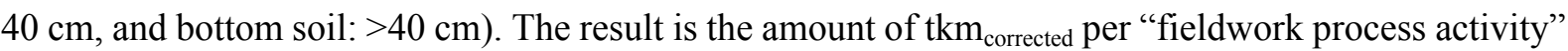
(and soil layer). With this result, the amount of $\mathrm{tkm}_{\text {corrected }}$ per "crop production activity" is calculated (per soil layer) (see also Figure S1).

\subsubsection{Axle load modeling}

The axle load modeling implemented in the template database is based on a calculation tool from Agroscope, which is available at the following website or via the following file-link:

http://www.services.art.admin.ch/traktor/d/tt2015d.html

http://www.services.art.admin.ch/traktor/Achslasten/Berechnungsprogramm-Achslasten.xlsx

The calculations are made for a static state. The information needed are

- Front axle load (tractor only) (W_front)

- Rear axle load (tractor only) (W_rear)

- Maximum rear axle load (W_rear_max)

- Transmission load (from attached machinery to rear axle) (W_transmission)

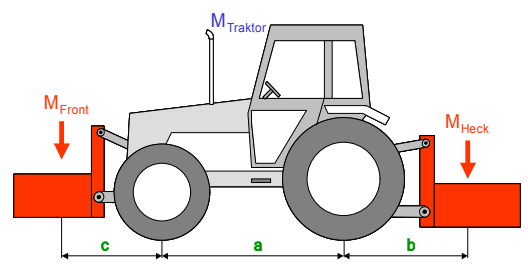

- Distances between wheels and between wheels and loads (a, b, c in Figure S2)

Figure S2: Figure from Acroscope calculation tool (see link above)

With this information, first the extra front weight (W_extra) needed is calculated (Equations 1-4; Matthias Stettler (BFH), personal communication), then the resulting effective loads (W_front_eff, W_rear_eff) are calculated.

$$
\begin{aligned}
& \text { W_rear }{ }^{*}=\text { W_rear }+ \text { W_transmission }+(\text { W_transmission } x \text { b/a }) \\
& \text { W_extra }=\text { W_rear }{ }^{*}-\text { W_rear_max } \\
& \text { W_front_eff }=W_{-} \text {front } \times a+W_{-} \text {extra } \times(a+c)-W \_ \text {transmission } \times \text { b) /a }
\end{aligned}
$$

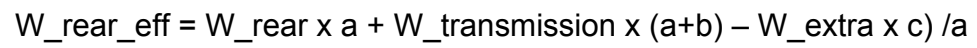

The information for these calculations is not available for Ecoinvent activities and assumptions had to be made. Some limits and boundary conditions help to get the estimates in a reasonable range. Detailed information for several tractor models can be found on www.traktorentest.ch. The balance between the axles seems to be somewhere between 40:60 (front:rear) and 50:50 so the assumption made was 45:55. 
The maximum rear axle load seems to be often a bit higher than total tractor weight, so the tractor weight was rounded up a bit for maximum rear axle load. Furthermore, for conventional couplings, the legal maximum transmission load is $2000 \mathrm{~kg}$ (in Switzerland) and only for low-lying heavy load couplings it is up to $3000 \mathrm{~kg}$ (only available for tractors with more than about $80 \mathrm{~kW}$ power and more than $5 \mathrm{t}$ weight), and extra front weights are usually between 400 and $1500 \mathrm{~kg}$ (Matthias Stettler (BFH), personal communication). Therefore, limits of $2000 \mathrm{~kg}$ for transmission load and $1500 \mathrm{~kg}$ for extra front weights were set. For Ecoinvent activities, this sometimes results in a rear axle overload, indicating that the tractor may be too small for the attached machinery. The effective front axle load should be more than $20 \%$ of total weight (Agroscope calculation tool). This was the case for all Ecoinvent activities. As the TONKM model uses an average between the full and the empty machinery, axle loads were calculated for the full and the empty machinery.

\subsubsection{Tire widths and pressures}

Tire widths are not considered in the model, which is a limitation. The two main settings in the original model are $430 / 530 \mathrm{~mm}$ (front/rear) width a tire pressure of 0.8 bar $(=80 \mathrm{kPa})$ and $350 / 450 \mathrm{~mm}$ (front/rear) width a tire pressure of $0.6 \mathrm{bar}(=60 \mathrm{kPa})(\mathrm{SI} 4)$. This is comparable to small and medium tractors of the newly modeled inventories with tire widths of $340 / 420 \mathrm{~mm}$ and $480 / 600 \mathrm{~mm}$ (SI3). Contact area is mainly has an influence on top soil compaction and limited effect on the depth affected by the load (Lamandé et al. 2018).

Tire pressure values were set to recommended pressure at a speed of $30 \mathrm{~km} / \mathrm{h}$ using the Terranimo online tool: https://www.terranimo.world/CH/expert/Default.aspx

Values for the rear axle are also documented in SI3, worksheet "terranimo".

\subsubsection{Crop transfer trailer modeling}

When harvesting, crops need to be unloaded from the harvester unto a transfer trailer that transports the off the field. It seems that this is generally missing in Ecoinvent activities as a) no transfer trailers exist as agricultural machinery and b) it is not clear whether this was somehow included in the transport that is part of "crop production activities". In order to model the impact on the field, additional modeling of transfer trailers and their travel on the field was necessary. It was assumed that each unloading of the harvester causes $100 \mathrm{~m}$ driven by the transfer trailer (i.e. one trip across a field of 1 ha $=100 \times 100 \mathrm{~m}$ ).

transfer trailer distance $[\mathrm{km} / \mathrm{kg}$ crop] $=0.1[\mathrm{~km}] /$ harvester load $[\mathrm{kg} \mathrm{crop}]$

The crop transfer trailers activities were added as technosphere input (like the other "fieldwork process activities") to the adapted "crop production activities" (they are all harvested with a combine harvester). REMARK with regard to handling data (see code, notebook 3): The input is in $\mathrm{km} / \mathrm{kg}$ crop and not as for other "fieldwork process activities" in ha/kg crop. Therefore, when dividing by land transformation [ha], i.e. the area required to produce $1 \mathrm{~kg}$ of product (Nemecek and Kägi 2007, p.138), the result is not the number of passes but the yield $[\mathrm{kg} / \mathrm{ha}]$. 


\subsubsection{Adapting the number of passes for case study "crop production activities"}

For wheat production, the Ecoinvent activity for France was used since it is part of the RoW dataset and close to potential yield (see SI2). For maize and soybean production, Ecoinvent RoW activities were used. It turned out that due to a special calculation procedure documented in Jungbluth et al. (2007), the number of passes for the various "fieldwork process" inputs can be unreasonable in these datasets: The area sowed and harvested for example can be smaller than the area that is needed for cultivation (i.e. the area transformed in the same Ecoinvent datasets (Nemecek and Kägi 2007, p.138)). As this is not reasonable and has an influence on the assessment of compaction, the amount of field process activities used (in ha) was adjusted (see SI2).

Although there seems to be less than yearly tillage for wheat and soybean production, there is no documentation whether the production systems should be considered to be "reduced tillage" or not. Therefore, for erosion modeling, it is still assumed that the systems can be considered "conventional tillage".

\subsection{Erosion inventory modeling}

The inventory modeling for erosion is limited to attaching C- and P-factors (and their sub-factors) to "crop production activities". Both factors range from 0 to 1 , indicating by how much they can prevent erosion calculated with the KRLS-factor. For all activities, those existing in the Ecoinvent database, conventional tillage and no conservation measures are assumed. Hence, the P-factor is 1 and the CPfactor is equal to the $\mathrm{C}$-factor. The only sub-factor considered in the $\mathrm{C}$-factor is the crop factor, which is taken from Panagos et al. (2015).

\subsection{Attaching compaction- and erosion-modeling to Ecoinvent activities}

\subsubsection{Technical implementation}

As the inventory modeling creates new elementary flow proxies, applying the presented method is only possible with a workaround for which we used the Brightway2 software (Mutel 2017) (otherwise the elementary flow proxies would need to be added to the Ecoinvent biosphere matrix).

The TONKM model computes compaction stress as corrected tkm per pass on a unit area of one hectare cultivated. This is calculated for each "fieldwork process activity". Then the number of passes per "fieldwork process activity" is calculated for each "crop production activity" from Ecoinvent datasets: The land transformed ("to" or "from") indicates the land needed to cultivate $1 \mathrm{~kg}$ of crop (the inverse of the yield) and the "fieldwork process" inputs to the "crop production activity" are usually given in ha. Furthermore, dividing the land transformed (in ha) by the land occupied (in ha-yr) gives the number of crop cycles per year. Using the passes per machinery and crop cycle and the number of crop cycles per year, the corrected tkm driven on a hectare per year, i.e. the compaction stress per year, of each "crop production activity" is calculated. For the final elementary flow proxy, this number is multiplied with 
the land occupation in ha-yr, resulting in a compaction-potential*area measure per amount of crop. Similarly, the CP-factor of a crop is multiplied with the land occupation in ha-yr, resulting in an erosionpotential*area-time measure per amount of crop (for a full calculation example including units see below).

The result of attaching compaction stress and CP-factors to all "crop production activities" is a lookup table, which can be used for further calculations (top right table in Figure S3). For inclusion in a regular LCA, the inventory needs to be calculated and the contributions of the "crop production activities" (in $\mathrm{kg}$ ) need to be extracted. These contributions can then be multiplied with the per-kg-values from the lookup table in order to add compaction and erosion elementary flow proxies to the inventory. Finally, these can be used with the regionalized CFs to calculate compaction and erosion impacts (see description of code below).

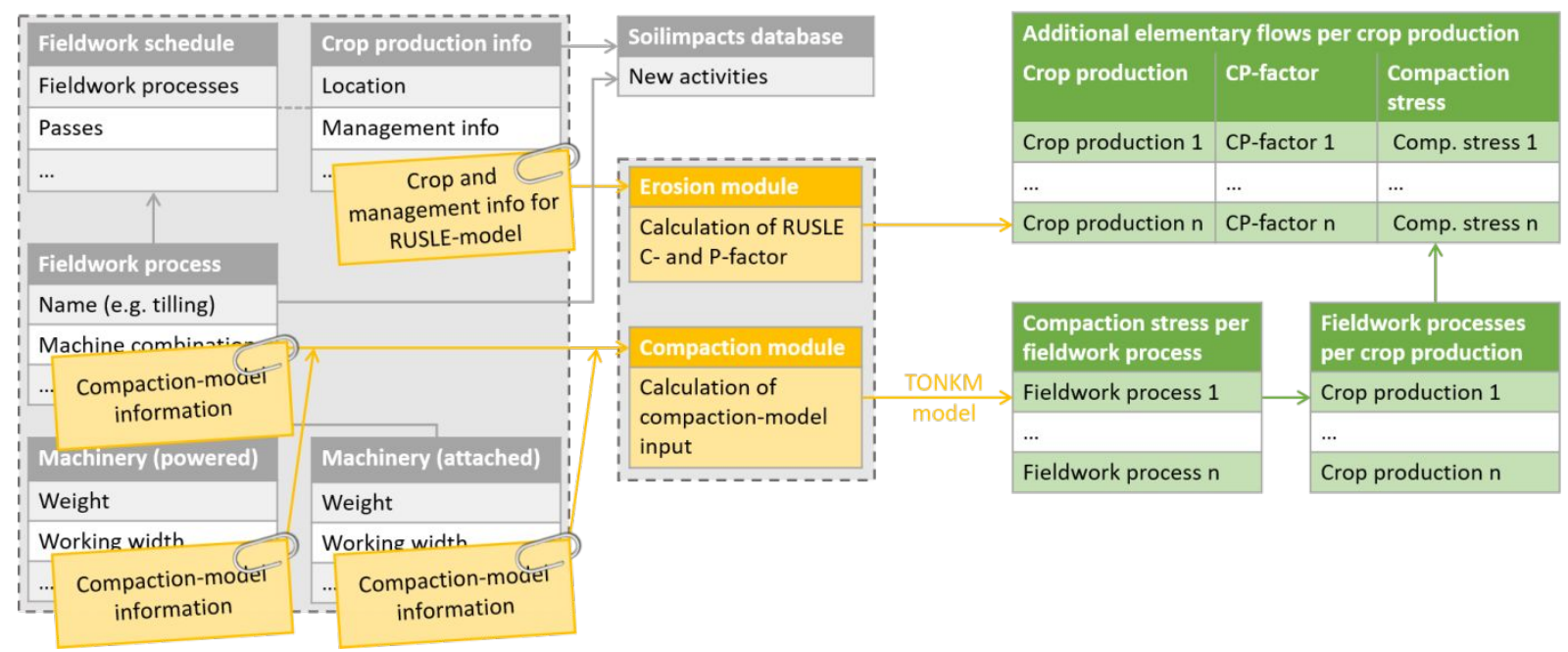

Figure S3: Schematic of data collection in the template database (boxes within dashed boxes) and first processing in the code: building the "soilimpacts" database and a table with the CP-factors and the compaction stress for all "crop production activities" of Ecoinvent and the new database

\subsubsection{Example}

The functional unit is the cultivation of $1000 \mathrm{~kg}$ of soybeans (Table S1). The yield is $2600 \mathrm{~kg} \mathrm{ha}^{-1}$ harvested twice a year (= two crop cycles per year). Thus, the production of $1000 \mathrm{~kg}$ of soybean needs $1000 / 5200=0.192$ ha-yr. Compaction impact potential of the inventory is based on the corrected tkm driven on 1 ha per cultivation. For the final elementary flow proxy, the compaction stress per year (i.e. the corrected tkm driven on 1 ha in a year $[(\mathrm{tkm} / \mathrm{ha}) / \mathrm{yr}])$ is multiplied with the land occupation [ha$\mathrm{yr} / \mathrm{kg}$ ] and the amount of crop produced $[\mathrm{kg}]$, resulting in a compaction-potential*area measure $[(\mathrm{tkm} / \mathrm{ha}-\mathrm{yr}) *$ ha-yr $=\mathrm{tkm}]$. The characterization factor translates the compaction stress into percentage soil productivity loss [\% ha-yr], so the unit of the CF for compaction is \% soil productivity loss per compaction stress [\% ha-yr / tkm].

The calculation for erosion is similar but the elementary flow proxy and the CF have different units. Erosion impact potential of the inventory is based on the CP-factor. For the final inventory result, the 
CP-factor is multiplied with the land use [ha-yr $/ \mathrm{kg}]$ and the amount of crop produced $[\mathrm{kg}]$, resulting in an impact-potential*area-time measure [ha-yr $\left.{ }_{\mathrm{cp}}\right]$. The erosion rate $[\mathrm{t} / \mathrm{ha}-\mathrm{yr}]$ is combined with the conversion factor [\% / ( $\mathrm{t} / \mathrm{ha}-\mathrm{yr})]$, resulting in a CF in $\%$. The conversion factor itself is a combination of erosion-yield loss factors [\%/ (t/ha)] and an assumed 50 years of impact. Impacts are calculated by multiplying the inventory results with the CFs. The unit is [\% productivity loss ha-yr] per amount of crop [kg]. With this impact, losses may be calculated for production in the following year(s). The impact of producing $1000 \mathrm{~kg}$ of soybean is $1.32 \%$ * ha-yr for compaction and $8.06 \% *$ ha-yr for erosion. If the soybean production continues for another year, the absolute losses are $13 \mathrm{~kg}(1000[\mathrm{~kg} / \mathrm{ha}-\mathrm{yr}] * 1.32$ [\%* ha-yr]) from bottom soil compaction and $81 \mathrm{~kg}$ from erosion.

Table S1: Example calculation of elementary flow proxy, CF, and impact for the production of $1000 \mathrm{~kg}$ soybean (cultivation with two crop cycles in one year)

\begin{tabular}{|c|c|c|c|c|c|c|c|c|}
\hline & \multicolumn{4}{|c|}{ Inventory } & \multirow[b]{2}{*}{ KRLS-factor } & \multirow[b]{2}{*}{$\begin{array}{c}\text { Conversion } \\
\text { factor }\end{array}$} & \multirow{2}{*}{$\begin{array}{c}\text { CF } \\
\text { Productivity } \\
\text { loss / IP*LU }\end{array}$} & \multirow{2}{*}{$\begin{array}{c}\text { Impact } \\
\text { Productivity } \\
\text { loss* area }\end{array}$} \\
\hline & $\begin{array}{c}\text { Functional } \\
\text { Unit }\end{array}$ & $\begin{array}{c}\text { Land Use } \\
\text { (LU) }\end{array}$ & $\begin{array}{c}\text { Compaction } \\
\text { Stress (CS) }\end{array}$ & CS*LU & & & & \\
\hline \multirow{2}{*}{ 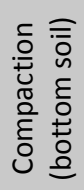 } & kg crop & ha-yr & (tkm/ha) / yr & $\begin{array}{c}\text { (tkm/ha-yr) } \\
\text { ha-yr }\end{array}$ & & & $\begin{array}{c}\% * \text { ha-yr / } \\
\text { tkm }\end{array}$ & $\% *$ ha-yr \\
\hline & 1000 & 0.192 & 112 & 21.5 & & & 0.0616 & 1.32 \\
\hline \multirow{2}{*}{$\begin{array}{l}\text { 음 } \\
\frac{0}{\text { บे }}\end{array}$} & kg crop & ha-yr & CP-factor & ha-yr ${ }_{C P}$ & $\mathrm{t} / \mathrm{ha}-\mathrm{yr} \mathrm{r}_{\mathrm{CP}}$ & $\begin{array}{c}\% / \\
\text { (t / ha-yr) }\end{array}$ & $\%$ & $\% *$ ha-yr \\
\hline & 1000 & 0.192 & 0.28 & 0.0 .0538 & 100 & 1.5 & 150 & 8.06 \\
\hline
\end{tabular}

\subsubsection{The template database and the code (ESD GitHub 2020)}

In a first step (Notebook 0), compaction- and erosion-relevant processes have been extracted from the Ecoinvent 3.5 database and fed into the template database (SI3). Then missing data for the compaction model was created using information from Nemecek and Kägi (2007) or literature.

The template database has two main sections with several spreadsheets for data entry: "Data collection" and "Data preparation" (Table S2). In the "Data collection" section, the user enters the information of new crop production or fieldwork process activities. It is also possible to modify assumptions made for Ecoinvent processes. In the "Data preparation" section, the user does need to make sure all new activities are listed but only very little data needs to be entered. In this section, the data is prepared to be read into code. The compaction module sheets include the axle load modeling. The erosion module sheets use Cand P-factors from Panagos et al. (2015a, b) and already calculates the combined CP-factor. Furthermore, the template database contains lists of Ecoinvent geographies for correct location labeling of activities.

Notebook 1 sets up a "soilimpacts" database in Brightway2 and adds new "fieldwork process activities" based on the information entered into the template database. 
Notebook 2 adds new "crop production activities" for the case study based on the information entered into the template database. As not all exchanges (resource inputs and emissions as well as technosphere inputs) are modeled (see 1.1), Notebook 2 cannot be run just like that but might need adaptations. The provided version was created for the case study example.

Notebook 3 attaches all compaction and erosion information to "crop production activities" (Figure S3) so in a next step, an inventory can be compared to this "list" and compaction and erosion impacts can be calculated. First, a first part of the compaction model is run with all fieldwork process activities in order to calculate compaction stress in tkm (for three soil layers) per functional unit of fieldwork process activity, e.g. per ha (most activities) or per bale (baling) or per kg (solid manure spreading). Second, for each "crop production activity", the amounts of "fieldwork process activities" inputs are multiplied with the compaction stress in tkm per functional unit of fieldwork process activity and summed up to get total compaction stress per "crop production activity". The output is a table with the CP-factors and the compaction stress (per kg) for all "crop production activities" of Ecoinvent and the new "soilimpacts" database. It is the summarized erosion and compaction inventory result. For the case study, this inventory output is used in the R code calculating the impacts of global crop production (ESD GitHub 2020).

Table S2: Structure of the template database for data entry

\begin{tabular}{|c|c|c|c|}
\hline & Sheet name & $\begin{array}{l}\text { Ecoinvent } \\
\text { data } \\
\text { included? }\end{array}$ & \\
\hline \multirow{5}{*}{ 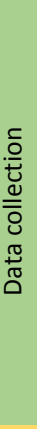 } & $\begin{array}{l}\text { 3a Crop } \\
\text { production } \\
\text { information }\end{array}$ & no & $\begin{array}{l}\text { This sheet contains general information about the crop such as name, location, yield, and } \\
\text { agricultural practice (input for erosion module) }\end{array}$ \\
\hline & $\begin{array}{l}\text { 1a Machinery } \\
\text { (powered) }\end{array}$ & yes & $\begin{array}{l}\text { This sheet contains specific information about the powered machinery (input for } \\
\text { compaction module) }\end{array}$ \\
\hline & $\begin{array}{l}\text { 1b Machinery } \\
\text { (attached) }\end{array}$ & yes & $\begin{array}{l}\text { This sheet contains specific information about the attached machinery (input for } \\
\text { compaction module) }\end{array}$ \\
\hline & $\begin{array}{l}2 \text { Field work } \\
\text { processes }\end{array}$ & yes & $\begin{array}{l}\text { This sheet combines machines into "fieldwork process activities" (input for compaction } \\
\text { module) }\end{array}$ \\
\hline & $\begin{array}{l}\text { 3b Fieldwork } \\
\text { schedule }\end{array}$ & no & $\begin{array}{l}\text { This sheet specifies the fieldwork schedule ("fieldwork process activities" and passes (and } \\
\text { date if available)) for a crop (used for database creation in Brightway2) }\end{array}$ \\
\hline \multirow{5}{*}{$\begin{array}{l}\frac{1}{0} \\
\frac{0}{0} \\
\frac{\pi}{\pi} \\
\frac{0}{0} \\
\frac{1}{2} \\
\frac{0}{0} \\
\frac{\pi}{\pi}\end{array}$} & $\begin{array}{l}\text { Inventory module } \\
\text { (machinery) }\end{array}$ & no & This sheet prepares the field work processes data for database creation in Brightway2 \\
\hline & $\begin{array}{l}\text { Compaction } \\
\text { module ecoinvent }\end{array}$ & yes, only & $\begin{array}{l}\text { This sheet prepares the machinery and field work processes data for compaction } \\
\text { calculation in Brightway } 2\end{array}$ \\
\hline & $\begin{array}{l}\text { Compaction } \\
\text { module database }\end{array}$ & no & $\begin{array}{l}\text { This sheet prepares the machinery and field work processes data for compaction } \\
\text { calculation in Brightway2 }\end{array}$ \\
\hline & $\begin{array}{l}\text { Erosion module } \\
\text { ecoinvent }\end{array}$ & yes, only & $\begin{array}{l}\text { This sheet prepares agricultural practice (assumed to be conventional) data for erosion } \\
\text { calculation in Brightway2 }\end{array}$ \\
\hline & $\begin{array}{l}\text { Erosion module } \\
\text { database }\end{array}$ & no & $\begin{array}{l}\text { This sheet prepares agricultural practice (from 3a Crop production information) data for } \\
\text { erosion calculation in Brightway } 2\end{array}$ \\
\hline
\end{tabular}




\section{Impact modeling}

\subsection{Time horizon}

The result of the TONKM model is the cumulative/time-integrated soil productivity loss (in \% ha-yr) due to compaction (= compaction loss $=\mathrm{CL}$ ) over a chosen time horizon (TH) (Equation 6). Topsoil losses occur in the first four years and those in the mid soil in the first ten years after the compaction event. Bottom soil losses are assumed to be permanent and calculated for a 50 year time horizon in the original model (Arvidsson and Håkansson 1991).

$C L_{\text {total }}=\int_{0}^{4} C L_{\text {top }}(t) d t+\int_{0}^{10} C_{\text {mid }}(t) d t+\int_{0}^{T H} C_{\text {bottom }}(t) d t$

Assuming continuous cultivation and yearly repetition, a steady state impact is reached in the top soil after four years and in the mid soil after ten years (and hence also in the top and mid soil combined after ten years). For the bottom soil, a time horizon has to be chosen. We took the 50 year time horizon from the original model as conservative baseline and performed a sensitivity analysis for time horizons of 10 , 20, 30, and 40 years. This model assumption of permanent impacts in the bottom soil lasting for 50 years is equivalent to assuming a recovery time of 50 years and therefore a steady state after 50 years. The long-term steady state is equal to the cumulative/time-integrated compaction losses of one compaction year $\left(C L_{\text {total }}\right.$ in Equation 6) as shown in Figure 2.

Larney et al. (2009) provide long-term data indicating that there are temporary and permanent yield losses due to erosion. Their results imply that the more erosion, the more permanent damage occurs. This is similar as for compaction, where the higher pressures on soil penetrate deeper into the soil and cause more permanent damage. However, the data from Larney et al. (2009) does not allow for modeling long-term steady state losses as for compaction. The soil removal depths in their experiments are 5, 10, 15 , and $20 \mathrm{~cm}$. Over 50 years, a cumulative erosion of $10 \mathrm{~cm}$ corresponds to $2 \mathrm{~mm} / \mathrm{year}$ or $30 \mathrm{t} / \mathrm{ha}-\mathrm{yr}$ (assuming a bulk density of $1.5 \mathrm{t} / \mathrm{m}^{3}$ ), which is close to "severe" erosion (33.6 $\mathrm{t} / \mathrm{ha}-\mathrm{yr}$ according to Stone (2015)). If the CP-factor is set to 0.3 (average of crop factors, see SI3, worksheet "C- and P-factor tables") and the time horizon to 50 years, the $77.5 \%$-percentile of erosion values computed (for the case study cropland area cells) corresponds to these cumulative $10 \mathrm{~cm}$ of erosion; the $85 \%$-percentile corresponds to $20 \mathrm{~cm}$. The corresponding yield losses depend on the erosion-yield loss factors (see 2.3.4). The data from Larney et al. (2009) can be used to calculate these factors for their experiments (Table S3): For $20 \mathrm{~cm}$ erosion, the steady state long term losses are 31\% (average of dryland and irrigated site), resulting in an erosion-yield loss factor of 0.014 . For $10 \mathrm{~cm}$ erosion, the losses are $21 \%$, resulting in an erosion-yield loss factor of 0.01 . This is at the lower limit of erosion-yield loss factors from literature (see 2.3.4 and SI5). Using the global factor of 0.02 , computed losses are $60 \%$ and $30 \%$, respectively. Case study erosion rates and the global erosion-yield loss factor might be rather conservative estimates compared to data from Larney et al. (2009). 
Table S3: Soil removal, permanent losses, and calculated loss rates based on Larney et al. (2009).

\begin{tabular}{c|c|c|c|cc} 
& dryland & irrigated & \multicolumn{3}{c}{ average } \\
\hline soil removal & \multicolumn{3}{|c|}{ permanent losses } & \multicolumn{2}{c}{ loss rates } \\
\hline $\mathrm{cm}$ & $\%$ & $\%$ & $\%$ & $\% / \mathrm{mm}$ & $\% /(\mathrm{t} / \mathrm{ha})$ \\
\hline 5 & 11.2 & 8.1 & 9.7 & 0.19 & 0.013 \\
10 & 23.3 & 18.0 & 20.7 & 0.21 & 0.014 \\
15 & 31.8 & 20.9 & 26.4 & 0.18 & 0.012 \\
20 & 34.6 & 27.1 & 30.9 & 0.15 & 0.010 \\
& & & average: & 0.18 & 0.012
\end{tabular}

The Larney et al. (2009) data shows a permanent impact for 16 years and there is no obvious trend for recovery. Whether yearly erosion rates (as computed by the RUSLE model) over 50 years result in the same permanent losses as induced by soil removal, cannot be answered. Furthermore, for $15 \%$ of cropland area cells, cumulative erosion over 50 years is larger than $20 \mathrm{~cm}$ and corresponding losses are unclear, i.e. there might be a limit before reaching $100 \%$ yield loss. Since we do not know that, we assumed a linear relationship (i.e. continuing losses) up to $100 \%$ losses, which is again a conservative estimate. As for compaction, we took the 50 year time horizon as a conservative baseline and performed a sensitivity analysis for 10, 20,30, and 40 years.

Implementing different time horizons is straightforward and simple since time horizon is a multiplier in the calculation of the bottom soil layer compaction CF and the erosion CF (see Equation 9 and 2.3.4). Results presented in the study are based on a 50-year time horizon. Another possibility would be to assume an upper and a lower time horizon representing the $97.5 \%$ - and the $2.5 \%$-percentiles and a (for example) log-normal distribution in order to perform a Monte Carlo analysis and compute a distribution of impacts. Figure S4 shows the result for wheat production (medium, conventional tillage) assuming time horizons of 80 and 20 years (i.e. 30 years above and below the 50 year time horizon) to represent the $97.5 \%$ - and the $2.5 \%$-percentiles. 


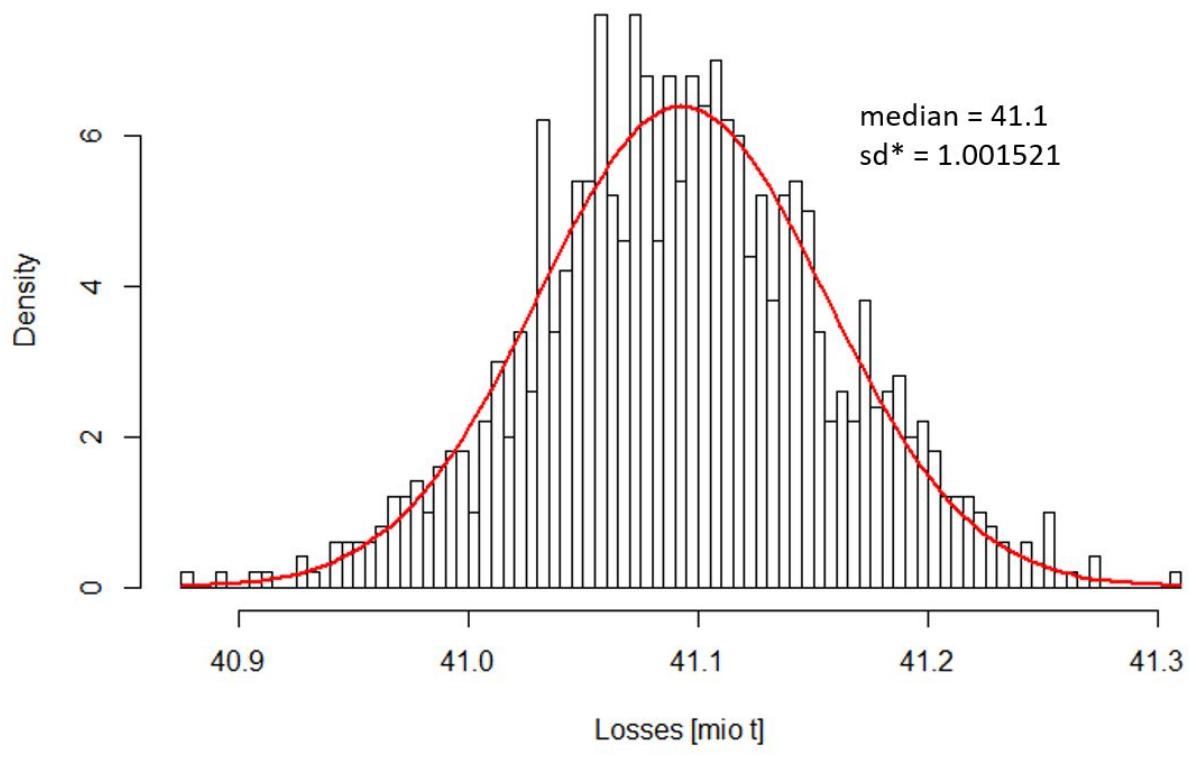

Figure S4: Monte Carlo result for yearly erosion losses for wheat production (medium, conventional tillage) assuming time horizons of 80 and 20 years (i.e. 30 years above and below the 50 year time horizon) to represent the $97.5 \%$ - and the $2.5 \%$ percentiles

\subsection{Compaction: Calculation of CFs for three soil layers}

Complete original and adapted TONKM model equations are compiled in SI4. Equations 7-9 show the part of the equations relevant for calculation of CFs. CFs for bottom soil compaction can be calculated by multiplying CFs for mid soil with a factor since the modeling equations have the same structure but different parameter values (Equation 10).

$\mathrm{CF}_{\text {topsoil }}=(\mathrm{swc} / 10 * 0.2625-0.056) * 0.00154 * \mathrm{cc}$

$\mathrm{CF}_{\text {midsoil }}=(\mathrm{swc} / 10-2) * 0.326 / 40$

$\mathrm{CF}_{\text {bottomsoil }}=(\mathrm{swc} / 10-2) * 0.272 / 400 *$ time horizon

Factor mid-to-bottom $=(0.272 / 400 *$ time horizon $) /(0.326 / 40)$

swc: soil water content; cc: clay content

Compaction CF modeling is based on data and calculations from Stoessel et al. (2018). Soil moisture on a global grid at $\sim 1 \mathrm{~km}$ resolution considering irrigation is based on soil moisture data from Trabucco (2010) and irrigation data from Siebert et al. (2013). Top soil clay content is based on soilgrids data (Hengl et al. 2017) and available in the ETH research collection (Sonderegger 2018). 


\subsection{Erosion: Calculation of the KRLS-factor}

The KRLS-factor was modeled starting from the data with the highest resolution, which is the Digital Elevation Model (DEM) used for the LS-factor (3 arc-seconds). The LS-factor raster was aggregated (computing the mean value) to the resolution of the K-factor raster ( 7.5 arc-seconds), the resulting KLSfactor was calculated and aggregated (computing the median value) to the resolution of the R-factor raster (30 arc-seconds), and finally the KRLS-factor was calculated (Figure S5). Uncertainties due to this spatial aggregation were not taken into account.

3 arc-seconds

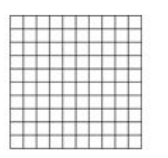

LS
7.5 arc-seconds

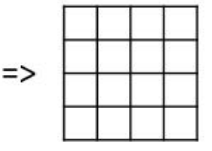

$\Rightarrow \quad$ LS
$\mathrm{X}$

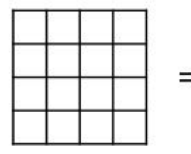

$\mathrm{K} \quad=$
30 arc-seconds

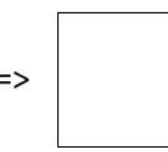

KLS

KLS $\quad \mathrm{X} \quad \mathrm{R}=\mathrm{KRLS}$

Figure S5: Aggregation and calculation procedure for the KRLS-factor.

\subsubsection{LS-factor}

For calculating the LS-factor, we used CGIAR-CSI SRTM data at $\sim 90 \mathrm{~m}$ resolution (Jarvis et al. 2008) for latitudes up to $60^{\circ} \mathrm{N}$ and GMTED2010 data (Danielson and Gesch 2011) at $\sim 1 \mathrm{~km}$ resolution for latitudes above $60^{\circ} \mathrm{N}$.

Since the SRTM data only covers latitudes up to $60^{\circ} \mathrm{N}$, it was combined with the GMTED data for latitudes above $60^{\circ} \mathrm{N}$. We processed the data for each UTM-zone separately using the raster-package and the RSAGA-package in R. First, we re-projected it to the corresponding UTM Coordinate Reference Systems (CRS) using RSAGA. Then we ran the algorithm by Desmet and Govers (1996) as implemented in RSAGA. Finally, we re-projected the data again to its original CRS (WGS84). All resulting raster tiles were aggregated to 7.5 arc-seconds resolution (computing the median value).

REMARK with regard to data handling: Results were multiplied by 100 in order to save the data in 16bit unsigned integers format. As the GMTED-data did not contain NoData-cells, we copied the NoData-cells from the K-factor raster to the LS-raster.

\subsubsection{K-factor}

For calculation of the K-factor, we used data from soilgrids.org (Hengl et al. 2017). The sand, silt, clay, and organic matter layers at $0 \mathrm{~cm}$ depth were downloaded from the website:

http://data.isric.org/geonetwork/srv/eng/catalog.search

- SNDPPT M sl1 250m.tif

- SLTPPT_M_sl1__250m.tif 
- CLYPPT M sl1 250m.tif

- ORCDRC_M $\bar{M}_{-}$slī_250m.tif

The equations used for calculation of the K-factor were those by Williams and Singh (1995) as presented in Scherer and Pfister (2015) Figure S6.

$$
\begin{gathered}
K=f_{\text {csand }} \cdot f_{\text {clay-silt }} \cdot f_{\text {org }} \cdot f_{\text {hsand }} \\
\text { where } \\
f_{\text {csand }}=0.2+0.3 \cdot \exp \left[-0.256 \cdot m_{\text {sand }} \cdot\left(1-m_{\text {silt }} / 100\right)\right] \\
f_{\text {clay-silt }}=\left(\frac{m_{\text {silt }}}{m_{\text {clay }}+m_{\text {silt }}}\right)^{0.3} \\
f_{\text {org }}=1-\frac{0.0256 \cdot \text { orgC }}{\operatorname{orgC~}+\exp (3.72-2.95 \cdot \text { orgC })} \\
f_{\text {hsand }}=1-\frac{0.7 \cdot\left(1-\frac{m_{\text {sand }}}{100}\right)}{1-\frac{m_{\text {sand }}}{100}+\exp \left[-5.51+22.9 \cdot\left(1-\frac{m_{\text {sand }}}{100}\right)\right]}
\end{gathered}
$$

Figure S6: Equations for calculation of the K-factor by Williams and Singh (1995) as presented in Scherer and Pfister (2015)

The results were multiplied by 0.1317 in order to convert them from US customary units to SI units (Foster et al. 1981).

\subsubsection{R-factor}

The European Soil Data Centre (ESDAC) provides the R-factor as a global raster dataset at $\sim 1 \mathrm{~km}$ resolution. The corresponding publication is Panagos et al. (2017).

\subsubsection{Conversion factors}

For the calculation of continental conversion factors, we took erosion-yield loss factors from den Biggelaar et al. (2004b, a). From the factors provided per crop and continent we calculated the continental median weighting with the continental area of the different crops. For the global factor, we calculated the median of continents weighing with crop area per continent (see SI5). These erosion-yield loss factors need to be multiplied with the chosen time horizon (50 years or the other time horizons used for sensitivity analysis, see 2.1) for calculation of conversion factors (see manuscript, section 2.3). The global conversion factor is $1(=0.02 * 50)$, the continental conversion factors range from 0.5 (Europe and North America) to 2 (Australia). While the continental scale may appear as too course of a geographic resolution, analysis of the data for maize, wheat, and soybean shows that values for the different soils within a continent are more homogenous than values for the different continents within a soil type (see SI5). For sensitivity analysis in the case study, we varied the global erosion-yield loss factor, setting it to $0.01,0.02$, or 0.03 (see SI7). 


\subsubsection{Results}

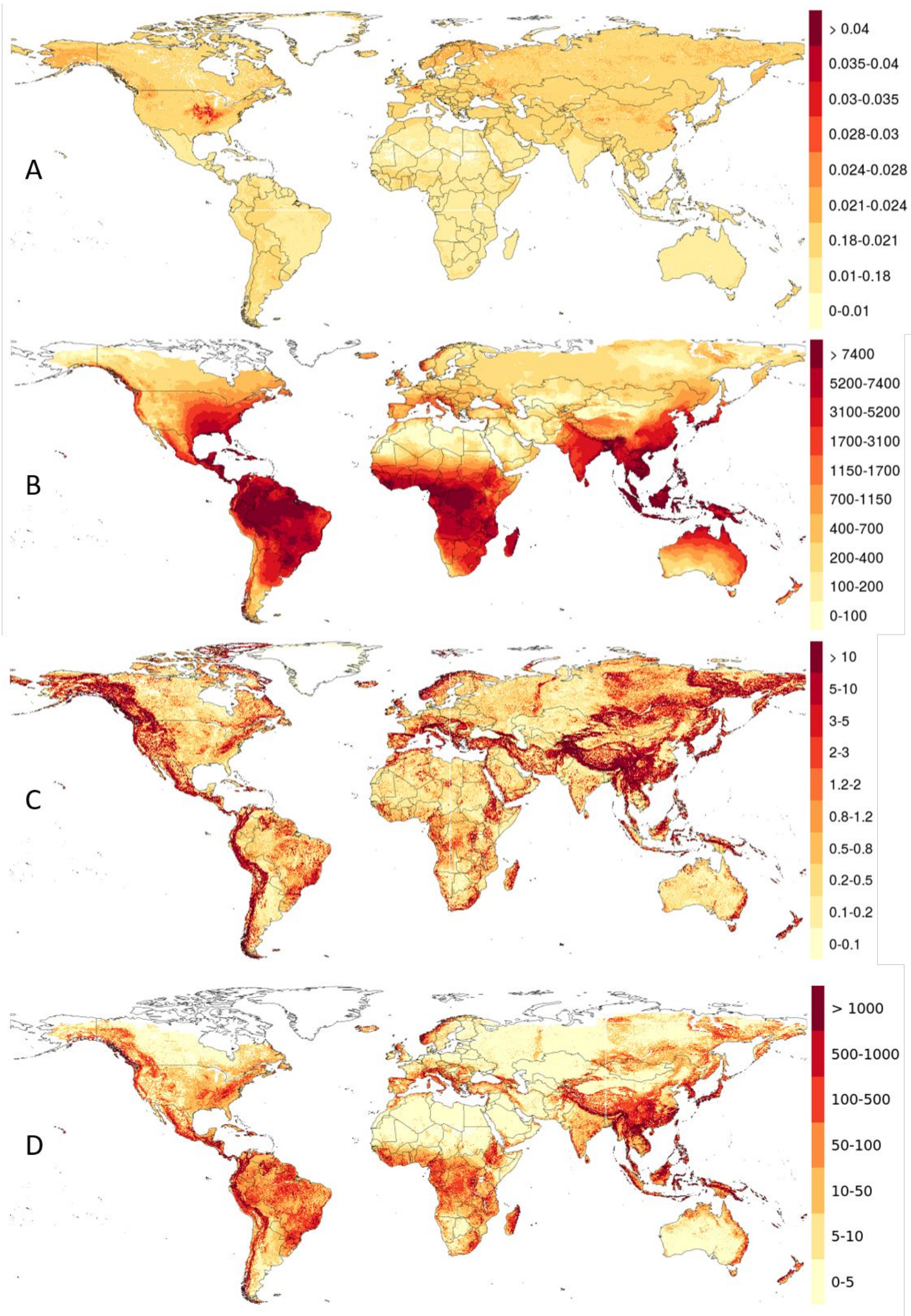

Figure S7: Maps for the K-factor (A), the R-factor (B), the LS-factor (B) and the KRLS-factor (D) 


\subsection{Characterization factors for cropland}
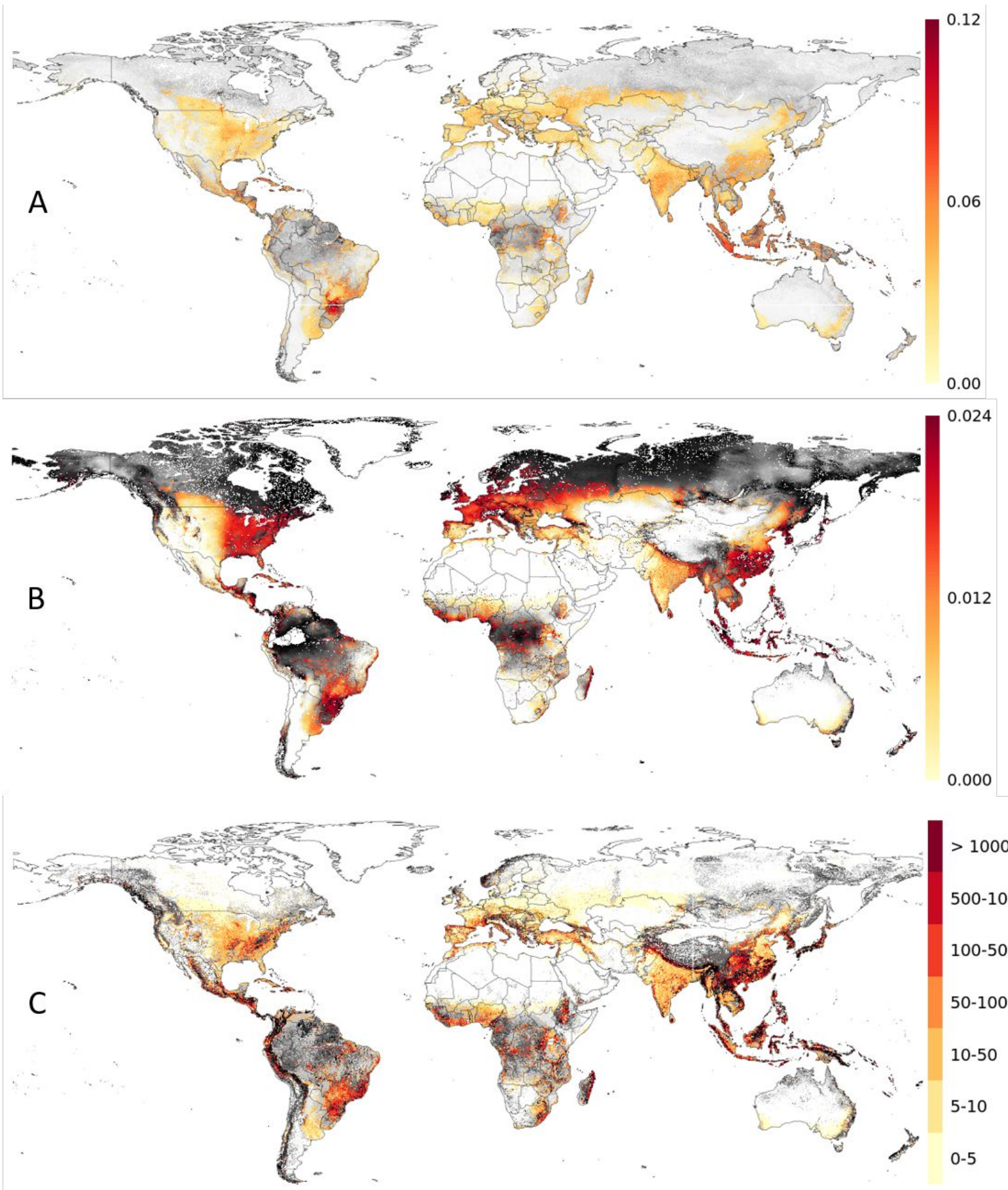

Figure S8: Characterization factors (CFs) for (A) top soil compaction, (B) mid soil compaction (both in \% productivity loss ha-yr $\mathrm{tkm}^{-1}$; note the different scale), and (C) water erosion [\% productivity loss]; CFs for bottom soil compaction can be calculated with a multiplication of CFs for mid soil compaction (B) (see 2.1); the red yellow-orange-red area shows cropland according to (Fritz et al. 2015), the grey area shows other land; the water erosion CFs correspond to the KRLS-factors since the multiplication with the global erosion-yield loss factor of 0.02 (see SI5) and a 50-year time horizon is a multiplication with 1; they are to be multiplied with the CP-factor ranging from 0 and 1 and then limited to $100 \%$ (see manuscript, section 2.3); 


\section{Uncertainties in characterization factors}

The uncertainties discussed here concern input parameter and data uncertainties, uncertainties in temporally aggregated CFs due to temporal variability, uncertainties in spatially aggregated CFs due to spatial variability, and uncertainties due to modeling and according assumptions.

\subsection{Input parameter and data uncertainties}

\subsubsection{Compaction: clay content}

Soil moisture and (for the top soil) clay content are the two input parameters for modeling compaction CFs. No uncertainties are provided for the data used.

As there is no uncertainty available for soilgrids data (Hengl et al. 2017) but clay content is part of Equation 7 used in the Monte Carlo simulation of top soil compaction, a rather cautious assumption was made: it was assumed that the clay content in $\%$ is normally distributed and $\pm 5 \%$ accurate.

\subsubsection{Erosion}

No uncertainties are provided for the input data used and no assumptions were made.

\subsection{Uncertainties due to temporal variability}

Uncertainties due to temporal variability could only be assessed for compaction, which depends on soil moisture.

\subsubsection{Compaction: soil moisture}

For soil moisture, we provide uncertainties due to temporal variability and monthly CFs. For calculations, we used data from the EU WATCH project (EU WATCH 2011), which was accessed in 2012. We used the monthly soil moisture data from 1971 to 2000 with a resolution of $0.5^{\circ}(\sim 56 \mathrm{~km}$ at the equator) to calculate variations between months and between years.

\subsubsection{Calculations}

The distributions of soil moisture between years (for a single month or for the yearly sum) and between months (within a year) are assumed to be log-normal as also precipitation is log-normally distributed (Pfister et al. 2009). This was visually tested for some examples. Medians $m$, dispersion factors $k$, and the multiplicative standard deviation $s d^{*}$ (the square root of $k$ ) were calculated to characterize distributions. The $95 \%$ confidence interval is then $[\mathrm{m} / \mathrm{k}, \mathrm{m} * \mathrm{k}]$ and the $68 \%$ confidence interval is [ $\mathrm{m}$ $/ s d^{*}, m^{*} s d^{*}$ ] (Slob 1994; Limpert et al. 2001). Accordingly, the 2.5\%- and the 97.5\%-percentile of the data were used to calculate $k$ (Equation 11) and $s d^{*}$ (Equation 12):

$m \cdot k / m / k=97.5 \%_{\text {percentile }} / 2.5 \%_{\text {percentile }}$ 
$\rightarrow k=\sqrt{97.5 \%_{\text {percentile }} / 2.5 \%_{\text {percentile }}}$
$\rightarrow s d^{*}=\sqrt{k}=\sqrt[4]{97.5 \% \text { percentile } / 2.5 \%_{\text {percentile }}}$

Where the $2.5 \%$-percentile is $0, s d^{*}$ was calculated as

$s d^{*}=\sqrt{k}=\sqrt{97.5 \% \text { percentile } / \text { median }}$

Where the median is $0, s d^{*}$ was calculated as

$s d^{*}=\sqrt{k}=\sqrt{97.5 \%_{\text {percentile }} / \text { mean }}$

Finally, where the mean is $0, s d^{*}$ was set to 1 (assuming that there was no uncertainty).

$m$ and $s d^{*}$ characterize a log-normal distribution fitted to the histogram of the data. For monthly CFs, the distributions were calculated for the 30 years of data for each month. For yearly CFs, the variation in between months as well as the variation in between years were calculated. For the monthly variations, first the median (over 30 years) for each month and then $m$ and $s d^{*}$ of these medians were calculated. For the yearly variations, first the sum of each year and then $m$ and $s d^{*}$ of these sums were calculated. Total $s d^{*}$ (Equation 16) was calculated from total $k$ (Equation 15), which was calculated as in (Pfister et al. 2009). If $s d^{*}$ monthly was $0, s d^{*}$ yearly was taken, if $s d^{*}$ yearly was $0, s d^{*}$ _monthly was taken.

$k_{\text {total }}=\exp \left(\sqrt{\ln \left(k_{\text {monthly }}\right)^{2}+\ln \left(k_{\text {yearly }}\right)^{2}}\right)$

$s d^{*}{ }_{\text {total }}=\sqrt{\exp \left(\sqrt{\ln \left(s d^{*}{ }_{\text {monthly }}{ }^{2}\right)^{2}+\ln \left(s d^{*}{ }_{\text {yearly }}{ }^{2}\right)^{2}}\right)}$

\subsubsection{Monte Carlo simulations}

$s d^{*}$ values as calculated above are applied to the soil water content values from (Stoessel et al. 2018). These soil water contents cover a scale from 10 (dry soil) to 50 (wet soil). The soil water content values are assumed to represent median values and $s d^{*}$ values are used to generate log-normal distributions around those medians. In a Monte Carlo simulation (1000 simulations), values from this distribution are selected (bounding them to 10 or 50 if they were out of these limits) and fed into the equations from the TONKM model. For the resulting 1000 simulated CFs, the median (as CF) and $s d^{*}$ (as the uncertainty measure) were calculated for each raster cell. Figure S9 shows the dispersion factor $k_{\text {total }}\left(=s d^{*}{ }_{\text {total }}^{2}\right.$, Equation 15) for compaction CFs. 

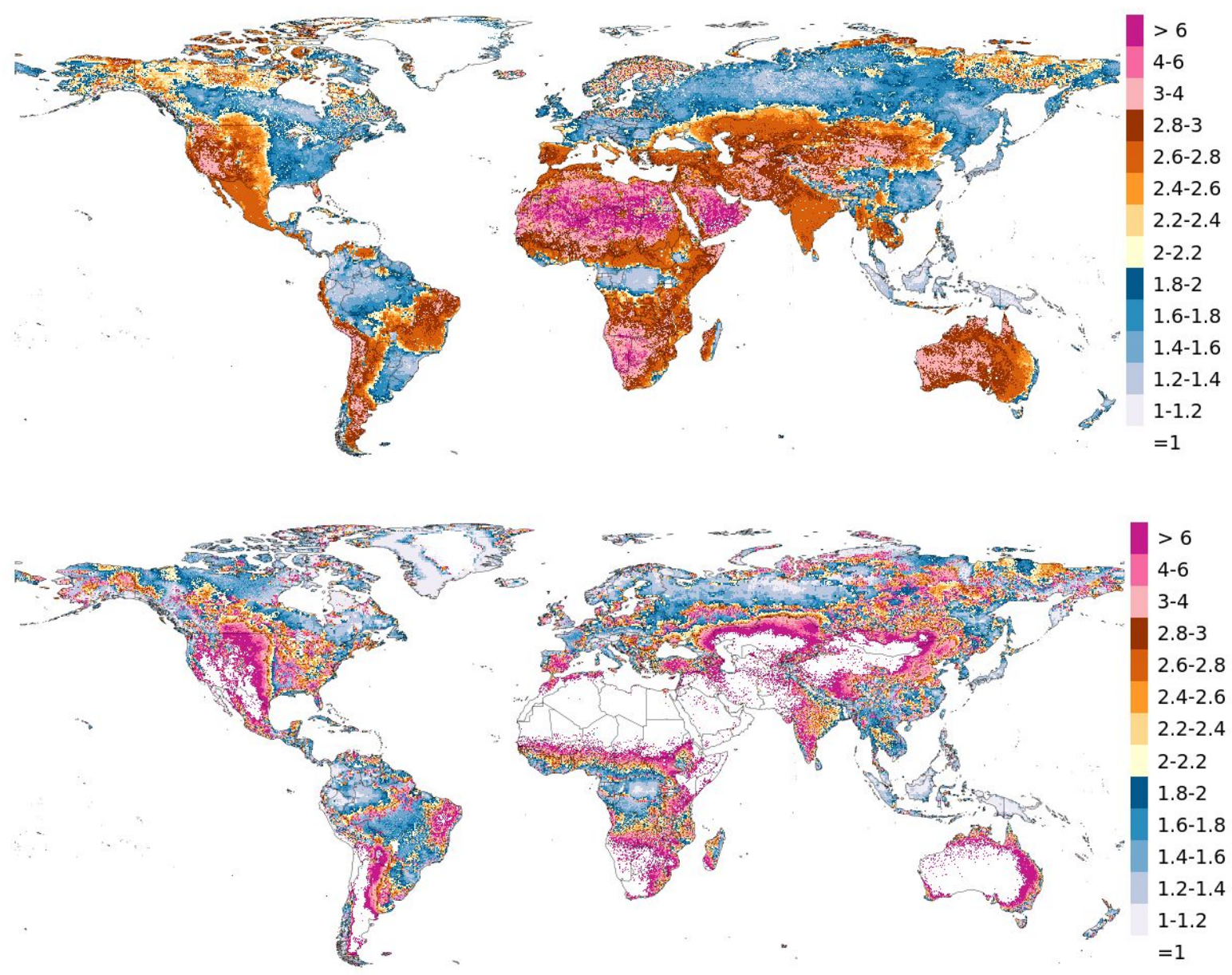

Figure S9: Dispersion factor $k_{\text {total }}$ (Equation 15) for compaction CFs in the top soil (top) and medium and bottom soil (bottom)

\subsubsection{Erosion: temporal variability of the R-factor}

While soil properties (K-factor) and topography (LS-factor) can be considered stable over time, rainfall and corresponding erosivity (R-factor) vary. Therefore, it would be preferable to have temporally resolved CFs, e.g. monthly CFs. At the global level however, monthly R-factors are not available. At the European level, Ballabio et al. (2017) used regression techniques with the REDES database (Rainfall Erosivity Database at the European Scale) and maps of climatic variables to estimate monthly R-factors. As they mention, the "monthly prediction is an order more difficult than the annual one as it is limited by the number of covariates and, for consistency, the sum of all months has to be close to annual erosivity". It is out of scope for this work to dig that deep into spatial statistics and derive global monthly R-factors. Hence, neither monthly characterization factors nor uncertainties due to temporal variations are provided.

\subsection{Accounting for spatial variability in aggregated CFs}

In order to calculate CFs for geo-units (i.e. countries and states), raster cells within a geo-unit were weighted with the total agricultural area per cell (calculated as the product of the cell size and the percentage of agricultural area in the cell). Weighted percentiles were then calculated using the 
"spatstat" package (version 1.58-2) in R: "The weighted median is a value $m$ such that the total weight of data to the left of $m$ is equal to half the total weight", whereby "the total weight of data" in our case is the total agricultural area of a geo-unit.

For erosion, the KRLS-value for each cell was used in computations. First, the area-weighted median was computed (Figure S10 shows the KRLS-raster and the weighting raster for a small geo-unit (Canton of Zurich) so the grid is visible). Then, the area-weighted 2.5\%- and 97.5\%-percentiles were computed and $s d^{*}$ was calculated assuming log-normal distribution (Equations $11 \mathrm{ff}$.). Figure S11 shows the histogram of the cropland weighted KRLS-factor for the geo-unit and the computed distribution using the median and $s d^{*}$.
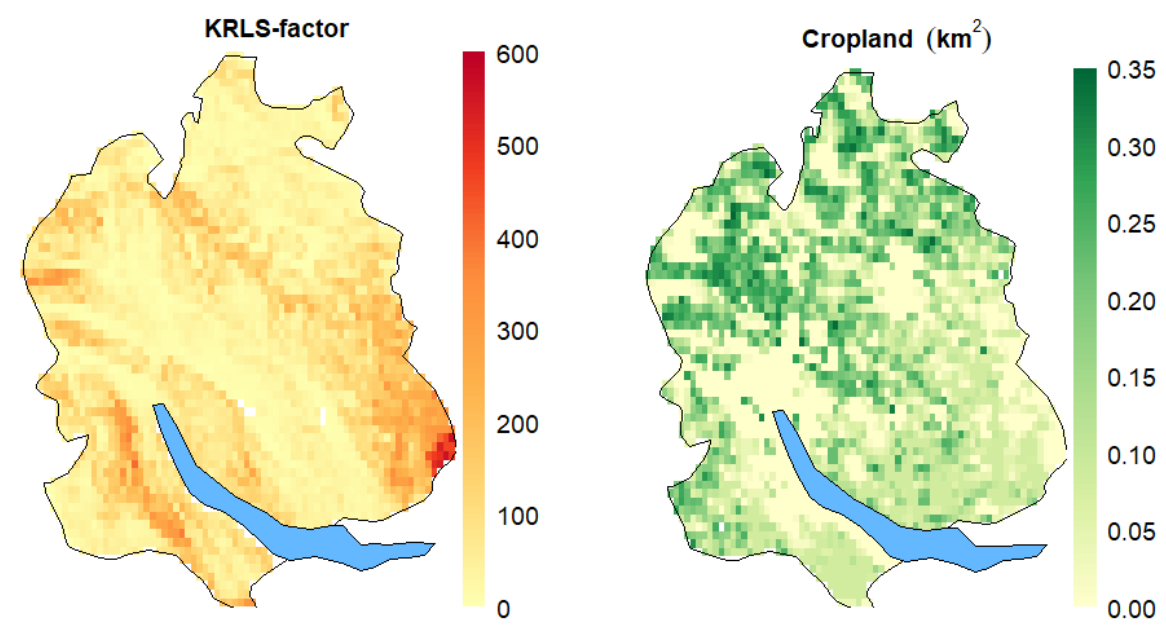

Figure S10: KRLS-raster and weighting raster for a small geo-unit (Canton of Zurich)

https://www.rdocumentation.org/packages/spatstat/versions/1.56-1/topics/weighted.median; accessed 16.08 .2019 


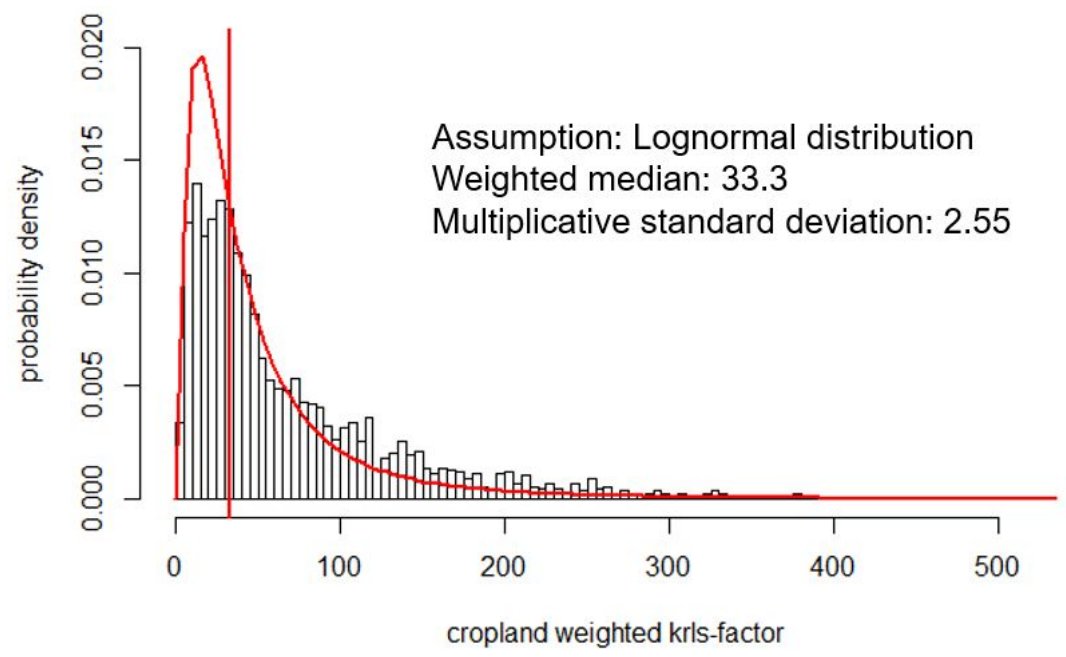

Figure S11: Histogram of the cropland weighted KRLS-factor and computed distribution (for the Canton of Zurich)

For compaction, the temporal uncertainty information for each cell was taken into account in a Monte Carlo simulation. For each simulation run, a value for each cell in the geo-unit was sampled from the distribution in the cell. Then the area-weighted median of all cells was computed. This resulted in 1000 simulated CFs. The distribution of these $1000 \mathrm{CFs}$ was assumed to be log-normal and and $s d^{*}$ was computed as the temporal uncertainty measure for the geo-unit (Equations $12 \mathrm{ff}$.). The temporal and spatial uncertainties were aggregated following Equations 15 and 16.

\subsection{Modeling uncertainties}

\subsubsection{Compaction}

One major problem of the model with regard to uncertainties is the use of an ordinal scale for soil moisture $(10-50=$ dry-wet). Original soil water content $(s w c)$ values $(0-100 \%)$ were translated to this scale (Equation 17). The validity of this translation would need to be tested in field trials.

$\mathrm{swc}=\mathrm{swc}_{\text {original }} / 2.5+10$

\subsubsection{Erosion}

For the LS-factor, a potential source of uncertainty is the SAGA GIS algorithm used for calculation of the LS-factor. For the K-factor, an empirical equation was used. Other equations exist (usually needing more input data) and could be tested to get an uncertainty range for the K-factor for future research. No uncertainty information was provided for the modeled R-factor. 


\section{Case study: additional results and discussion}

\subsection{Crop data}

The data from Monfreda et al. (2008) provides area harvested in hectares and as area fraction, i.e. areas harvested more than once a year are counted more than once, as well as cropland area fraction. The actually cultivated area was calculated as follows (implemented in R code, see ESD GitHub (2020) :

crop-cycles $_{\text {Monfreda }}=$ harvested-area_fraction / cropland_fraction

actual-cultivated-area $=$ harvested-area_hectares $/$ crop-cycles $_{\text {Monfreda }}$

Then the potential production was calculated using the potential yields from Monfreda et al. (2008) and the number of crop cycles as reported in the Ecoinvent activities:

potential production [t/yr] $=$ actual-area [ha] ${ }^{*}$ potential yield [t/ha-cycle] ${ }^{*}$ crop-cycles [cycles/yr]

Table S4 shows a comparison of data used in the calculations with data from FAO (2019). Numbers for global production, area, and yield are shown for the three crops (wheat, maize, and soybean). These numbers consider one crop cycle.

Table S4: Comparison of data used in the calculations with data from FAO with regard to global production, area, and yield for one crop cycle of the three crops (wheat, maize, and soybean); act. = actual, pot. = potential

\begin{tabular}{|c|c|c|c|c|c|c|c|c|c|c|}
\hline \multirow{4}{*}{$\begin{array}{l}\text { Crop production } \\
\text { activity }\end{array}$} & \multicolumn{3}{|c|}{ Area harvested } & \multicolumn{2}{|c|}{ Average yield } & Crop & \multicolumn{4}{|c|}{ Production } \\
\hline & \multicolumn{3}{|c|}{ mio ha $*$ crop-cycles/yr } & \multirow{2}{*}{\multicolumn{2}{|c|}{$\begin{array}{c}\text { t / ha / crop- } \\
\text { cycle } \\
\text { Monfreda/ } \\
\text { calculated }\end{array}$}} & $1 / \mathrm{yr}$ & \multicolumn{4}{|c|}{ mio $\mathrm{t} / \mathrm{yr}$} \\
\hline & \multirow{2}{*}{$\begin{array}{c}\text { Monfreda } \\
2000\end{array}$} & \multirow{2}{*}{$\begin{array}{l}\text { FAO } \\
2000\end{array}$} & \multirow{2}{*}{$\begin{array}{l}\text { FAO } \\
2016\end{array}$} & & & \multirow[t]{2}{*}{ Ecoinvent } & \multicolumn{2}{|c|}{$\begin{array}{l}\text { Monfreda/ } \\
\text { calculated }\end{array}$} & \multirow{2}{*}{$\begin{array}{l}\text { FAO } \\
2000\end{array}$} & \multirow{2}{*}{$\begin{array}{l}\text { FAO } \\
2016\end{array}$} \\
\hline & & & & act. & pot. & & act. & pot. & & \\
\hline $\begin{array}{l}\text { Wheat (large, } \\
\text { conventional) }\end{array}$ & 206 & 215 & 220 & 2.72 & 4.40 & 1.00 & 560 & 907 & 585 & 749 \\
\hline $\begin{array}{l}\text { Maize (large, } \\
\text { conventional) }\end{array}$ & 133 & 137 & 195 & 4.45 & 7.01 & 1.71 & 1016 & 1601 & 592 & 1100 \\
\hline $\begin{array}{l}\text { Soybean (large, } \\
\text { conventional) }\end{array}$ & 73 & 74 & 122 & 2.22 & 2.66 & 2.00 & 323 & 387 & 161 & 336 \\
\hline
\end{tabular}

Data in Table S4 shows that the areas harvested from Monfreda et al. (2008) correspond well to those from FAO for the year 2000, which was to be expected as the former builds on the latter. However, in 2016, more area was used for all three crops, especially for soybean (+ $64 \%)$ and maize $(+43 \%)$. Therefore, the case study example using old (but the only available gridded global) data clearly underestimates the total crop area of today. The area harvested considers crop cycles, so areas harvested more than once a year are counted more than once. However, as the comparison with the calculated actual area shows, this is rarely the case as the two areas are almost the same. This is different for the Ecoinvent activities where maize is considered to be harvested 1.71 times per year (on average) and 
soybean twice, and accordingly the calculated actual production is much larger than FAO data for maize and soybean. Although these harvest rates might not be possible everywhere in the world, there seems to be some potential for increasing production per area by harvesting more often. However, as this also implies more fieldwork per year, this would also have consequences for compaction.

\subsection{Characterization factors and impacts}

Since data from Monfreda et al. (2008) is at $10 \mathrm{~km}$ resolution, CFs were aggregated to $10 \mathrm{~km}$ resolution. Cropland area weighted medians were computed as for aggregation for geo-units (see 3.3). Where cropland areas did not match, i.e. where there was cropland according to Monfreda et al. (2008) but not to Fritz et al. (2015), the unweighted median was computed.

\subsection{Compaction: soil layer contributions}

Table S5 shows soil productivity losses due to compaction for the small, medium, and large versions of wheat production for the different soil layers. Results are shown in absolute (million tons per year) and relative values (\% per year). Furthermore, the contribution of each soil layer to total losses is shown in the last column.

Table S5: Soil productivity losses due to compaction for the small, medium, and large versions of wheat production for the different soil layers as well as the contribution of each soil layer to total losses

\begin{tabular}{|c|c|c|c|c|}
\hline \multirow[t]{2}{*}{ Crop production activity } & Soil layer & Compaction losses & Compaction losses & Soil layer contribution \\
\hline & & $\operatorname{miot} / \mathrm{yr}$ & $\% / \mathrm{yr}$ & $\%$ \\
\hline \multirow[t]{4}{*}{ wheat production, global, small } & top soil & 38.7 & 3.28 & 74.3 \\
\hline & mid soil & 4.7 & 0.47 & 10.6 \\
\hline & bottom soil & 6.5 & 0.67 & 15.1 \\
\hline & TOTAL & 49.9 & 4.42 & \\
\hline \multirow[t]{4}{*}{ wheat production, global, medium } & top soil & 43.0 & 3.29 & 54.0 \\
\hline & mid soil & 9.2 & 0.85 & 14.0 \\
\hline & bottom soil & 20.3 & 1.95 & 32.0 \\
\hline & TOTAL & 72.5 & 6.09 & \\
\hline \multirow[t]{4}{*}{ wheat production, global, large } & top soil & 45.8 & 3.22 & 47.7 \\
\hline & mid soil & 11.3 & 1.00 & 14.8 \\
\hline & bottom soil & 27.1 & 2.53 & 37.5 \\
\hline & TOTAL & 84.2 & 6.75 & \\
\hline
\end{tabular}

\subsection{Erosion: net erosion sensitivities}

The RUSLE model as used here only accounts for soil losses. Neither soil deposition from upstream erosion nor natural soil formation is considered. Furthermore, also natural vegetation, e.g. forest or grassland, has "crop" factors. Accordingly, while the RUSLE computes a gross erosion rate, the net effects for soil formation and "natural erosion" could be taken into account (Equation 21).

$\left[\left(\mathrm{CP}-\mathrm{CP}_{\text {Natural_Vegetation }}\right){ }^{*} \mathrm{KRLS}-\right.$ soil formation $]{ }^{*}$ conversion factor $=\%$ soil productivity loss 
Equation 21 was applied with a conservatively estimated CP-factor of 0.01 for natural vegetation (see SI5) and a conservatively estimated global soil formation rate of $0.05 \mathrm{~mm}$ per year or $0.75 \mathrm{t}$ per ha and year (assuming a bulk density of $1.5 \mathrm{t} / \mathrm{m}^{3}$ ) (Montgomery 2007; Núñez et al. 2013) (see SI5). Table S6 shows the results for applying Equation 21 to the case study. The contributions of the two net effects, i.e. considering soil formation and considering "natural erosion", were also assessed separately. For both net effects, differences are rather small, i.e. less than $5 \%$, except for considering soil formation for wheat (14.1\%). The combined effect is the sum of the two single effects. With regard to uncertainties involved, e.g. those of crop factors alone, it is justifiable to neglect the net effects.

Table S6: Gross and net erosion induced soil productivity losses considering soil formation or the CP-factor of natural vegetation

\begin{tabular}{|l|c|c|c|c|c|c|c|}
\hline \multirow{2}{*}{} & \multicolumn{4}{|c|}{ Soil productivity losses } & \multicolumn{3}{c|}{ Difference net-gross } \\
\cline { 2 - 8 } & gross & $\begin{array}{c}\text { net } \\
\text { (formation) }\end{array}$ & $\begin{array}{c}\text { net } \\
\text { (CP natural) }\end{array}$ & $\begin{array}{c}\text { net } \\
\text { (combined) }\end{array}$ & formation & CP natural & combined \\
\cline { 2 - 8 } & mio t / yr & mio t / yr & mio t / yr & mio t / yr & $\%$ & $\%$ & $\%$ \\
\hline wheat & 48 & 41 & 46 & 39 & -14.1 & -4.0 & -18.1 \\
\hline maize & 338 & 327 & 333 & 322 & -3.2 & -1.5 & -4.7 \\
\hline soybean & 57 & 54 & 55 & 52 & -5.0 & -2.8 & -7.8 \\
\hline
\end{tabular}

\section{Practical application}

Since our soil-degradation assessment methods are not based on existing elementary flows, they cannot yet be used in a straightforward manner with existing inventory databases. Therefore, we provide two tools to facilitate their use. First, the provided database template (SI3) guides the collection of all necessary data and facilitates the modelling of (a) Ecoinvent-compatible "fieldwork process activities", (b) the modelling of axle loads and other processing of inventory data for use in the TONKM model, and (c) the calculation of CP-factors. Second, the provided code (ESD GitHub 2020) allows (a) attaching the information from the template to Ecoinvent activities or to put it into a newly built database, (b) running the TONKM model, and (c) attaching the compaction and erosion information to an LCI.

For the practitioner, this means:

1. Collect inventory data using the template database (further instructions and minimal data requirements needed for compaction and erosion modeling are listed there).

2. Use the python code (notebooks 1-3) to create an inventory with crop production activities that contain compaction and erosion information (see 1.4.1 and Figure S3).

3. Use this information in your assessment (as for example done for the case study). 


\section{References}

Arvidsson J, Håkansson I (1991) A model for estimating crop yield losses caused by soil compaction. Soil Tillage Res 20:319-332. doi: 10.1016/0167-1987(91)90046-Z

Ballabio C, Borrelli P, Spinoni J, et al (2017) Mapping monthly rainfall erosivity in Europe. Sci Total Environ 579:1298-1315. doi: 10.1016/j.scitotenv.2016.11.123

Danielson JJ, Gesch DB (2011) Global Multi-resolution Terrain Elevation Data 2010 (GMTED2010). US Geol Surv 26

den Biggelaar C, Lal R, Wiebe K, et al (2004a) The Global Impact Of Soil Erosion On Productivity*. II: Effects On Crop Yields And Production Over Time. Adv Agron 81:49-95. doi: 10.1016/S00652113(03)81002-7

den Biggelaar C, Lal R, Wiebe K, Breneman V (2004b) The Global Impact Of Soil Erosion On Productivity. I: Absolute and Relative Erosion-induced Yield Losses. Adv Agron 81:1-48. doi: 10.1016/S0065-2113(03)81001-5

Ecoinvent (2018) Ecoinvent 3.5. https://www.ecoinvent.org/database/ecoinvent-35/ecoinvent-35.html. Accessed 24 May 2019

ESD GitHub (2020) Code for Sonderegger et al. (2020) Assessing impacts on the natural resource soil in Life Cycle Assessment - methods for compaction and water erosion. https://github.com/ethzesd/compaction_erosion_sonderegger_2020

EU WATCH (2011) WATCH 20th Century Model Output Datasets. http://www.waterandclimatechange.eu/about/watch-20th-century-model-output-datasets

FAO (2019) FAOSTAT. http://www.fao.org/faostat/en/\#data

Foster GR, Mccool DK, Renard KG, Moldenhauer WC (1981) Conversion of the universal soil loss equation to SI metric units. J Soil Water Conserv 36:355-359

Fritz S, See L, McCallum I, et al (2015) Mapping global cropland and field size. Glob Chang Biol 21:1980-92. doi: $10.1111 / \mathrm{gcb} .12838$

Gazzarin C (2018) Maschinenkosten 2018

Hengl T, Jesus JM De, Heuvelink GBM, et al (2017) SoilGrids250m : Global gridded soil information based on machine learning. PLoS One 12:1-40. doi: 10.1371/journal.pone.0169748

Jarvis A, Reuter HI, Nelson A, Guevara E (2008) Hole-filled SRTM for the globe Version 4, available from the CGIAR-CSI SRTM 90m Database (http://srtm.csi.cgiar.org).

Jungbluth N, Faist Emmenegger M, Dinkel F, et al (2007) Life cycle inventories of Bioenergy

Lamandé M, Greve MH, Schjønning P (2018) Risk assessment of soil compaction in Europe - Rubber tracks or wheels on machinery. Catena 167:353-362. doi: 10.1016/j.catena.2018.05.015

Larney FJ, Janzen HH, Olson BM, Olson AF (2009) Erosion-productivity-soil amendment relationships for wheat over 16 years. Soil Tillage Res 103:73-83. doi: 10.1016/j.still.2008.09.008

Limpert E, Stahel WA, Abbt M (2001) Log-normal Distributions. 51:341-352. doi: 10.1641/0006- 
3568(2001)051[0341:LNDATS]2.0.CO;2

Monfreda C, Ramankutty N, Foley JA (2008) Farming the planet: 2. Geographic distribution of crop areas, yields, physiological types, and net primary production in the year 2000. Global Biogeochem Cycles 22:1-19. doi: 10.1029/2007GB002947

Montgomery DR (2007) Soil erosion and agricultural sustainability. Proc Natl Acad Sci U S A 104:13268-72. doi: 10.1073/pnas.0611508104

Mutel C (2017) Brightway: An open source framework for Life Cycle Assessment. J Open Source Softw 2:236. doi: $10.21105 /$ joss.00236

Nemecek T, Kägi T (2007) Life Cycle Inventories of Agricultural Production Systems, ecoinvent report No. 15

Núñez M, Antón A, Muñoz P, Rieradevall J (2013) Inclusion of soil erosion impacts in life cycle assessment on a global scale: application to energy crops in Spain. Int J Life Cycle Assess 18:755767. doi: $10.1007 / \mathrm{s} 11367-012-0525-5$

Panagos P, Borrelli P, Meusburger K, et al (2015a) Estimating the soil erosion cover-management factor at the European scale. Land use policy 48:38-50. doi: 10.1016/j.landusepol.2015.05.021

Panagos P, Borrelli P, Meusburger K, et al (2015b) Modelling the effect of support practices (P-factor) on the reduction of soil erosion by water at European scale. Environ Sci Policy 51:23-34. doi: 10.1016/j.envsci.2015.03.012

Panagos P, Borrelli P, Meusburger K, et al (2017) Global rainfall erosivity assessment based on hightemporal resolution rainfall records. Sci Rep 7:1-12. doi: 10.1038/s41598-017-04282-8

Pfister S, Koehler A, Hellweg S (2009) Assessing the Environmental Impact of Freshwater Consumption in Life Cycle Assessment. Environ Sci Technol 43:4098-4104. doi: $10.1021 / \mathrm{es} 802423 \mathrm{e}$

Python (2019) Python programming language

Scherer L, Pfister S (2015) Modelling spatially explicit impacts from phosphorus emissions in agriculture. Int J Life Cycle Assess 20:785-795. doi: 10.1007/s11367-015-0880-0

Siebert S, Henrich V, Frenken K, Burke J (2013) Global Map of Irrigation Areas version 5. Rheinische Friedrich-Wilhelms-University, Bonn, Germany / Food and Agriculture Organization of the United Nations, Rome, Italy

Slob W (1994) Uncertainty Analysis in Multiplicative Models. Risk Anal 14:571-576. doi: 10.1111/j.1539-6924.1994.tb00271.x

Sonderegger $\mathrm{T}$ (2018) Assessing the environmental impacts of soil compaction in Life Cycle Assessment - supplementary data. https://doi.org/10.3929/ethz-b-000253177

Stoessel F, Sonderegger T, Bayer P, Hellweg S (2018) Assessing the environmental impacts of soil compaction in Life Cycle Assessment. Sci Total Environ 630:913-921. doi: 10.1016/j.scitotenv.2018.02.222

Stone RP (2015) Factsheet, Universal Soil Loss Equation (USLE). 
http://www.omafra.gov.on.ca/english/engineer/facts/12-051.htm\#t6. Accessed 19 Aug 2019

Trabucco A (2010) High-Resolution Global Soil-Water Balance Explicit for Climate - Standard Vegetation and Soil Conditions

Williams JR, Singh VP (1995) The EPIC model. In: Singh VP (ed) Computer models of watershed hydrology. pp 909-1000 